\title{
Correlations in sleeping patterns and circadian preference between spouses
}

Rebecca C Richmond*1,2 ${ }^{* 1}$ Laurence J Howe ${ }^{1,2}$, Karl Heilbron ${ }^{3}$, Samuel Jones ${ }^{4}$, Junxi Liu ${ }^{1,2}, 23$ andMe Research Team ${ }^{3}$, Xin Wang ${ }^{3}$, Michael N Weedon ${ }^{5}$, Martin K Rutter ${ }^{6,7}$, Deborah A Lawlor ${ }^{1,2,8}$, George Davey Smith ${ }^{1,2,8}$, Céline Vetter ${ }^{9}$

1. Medical Research Council Integrative Epidemiology Unit, University of Bristol, Bristol, BS8 2BN, UK

2. Population Health Sciences, Bristol Medical School, University of Bristol, Barley House, Oakfield Grove, Bristol, BS8 2BN, UK

3. 23andMe, Inc., $223 \mathrm{~N}$ Mathilda Avenue, Sunnyvale, CA, 94086, USA

4. Institute for Molecular Medicine FIMM, HiLIFE, University of Helsinki, Helsinki, Finland

5. Genetics of Complex Traits, University of Exeter Medical School, Exeter, UK

6. Division of Endocrinology, Diabetes \& Gastroenterology, School of Medical Sciences, Faculty of Biology, Medicine and Health, University of Manchester, Manchester, UK

7. Diabetes, Endocrinology and Metabolism Centre, Manchester University NHS Foundation Trust, Manchester Academic Health Science Centre, Manchester, UK

8. National Institute of Health Research Biomedical Research Centre, University of Bristol, UK

9. Circadian and Sleep Epidemiology Laboratory, Department of Integrative Physiology, University of Colorado Boulder, Boulder, CO, USA 
medRxiv preprint doi: https://doi.org/10.1101/2022.01.13.22269233; this version posted January 13, 2022. The copyright holder for this preprint

(which was not certified by peer review) is the author/funder, who has granted medRxiv a license to display the preprint in perpetuity.

It is made available under a CC-BY 4.0 International license.

\section{Abstract}

Spouses may affect each other's sleeping behaviour. In 47,420 spouse-pairs from the UK Biobank, we found a weak positive phenotypic correlation between spouses for self-reported sleep duration ( $r=0.11$; $95 \% \mathrm{Cl}=0.10,0.12$ ) and a weak inverse correlation for chronotype (diurnal preference) ( $\mathrm{r}=-0.11 ;-0.12$, 0.10 ), which replicated in up to 127,03523 andMe spouse-pairs. Using accelerometer data on 3,454 UK Biobank spouse-pairs, the correlation for derived sleep duration was similar to self-report $(r=0.12 ; 0.09$, $0.15)$. Timing of diurnal activity was positively correlated $(r=0.24 ; 0.21,0.27)$ in contrast to the inverse correlation for chronotype. In Mendelian randomization analysis, positive effects of sleep duration (mean difference $=0.13 ; 0.04,0.23$ SD per SD) and diurnal activity $(0.49 ; 0.03,0.94$ ) were observed, as were inverse effects of chronotype $(-0.15 ;-0.26,-0.04)$ and snoring $(-0.15 ;-0.27,-0.04)$. Findings support the notion that an individual's sleep may impact that of their partner, with implications for sleep health. 


\section{Introduction}

2 Insufficient and disturbed sleep are pervasive features of society, with more than a quarter of US adults

3 reporting sleeping six or fewer hours per night (1), and over a third of adults reporting insomnia (2). In

4 addition to insomnia and short sleep duration, symptoms of sleep disturbance include long sleep

5 duration, difficulty waking up in the morning and daytime sleepiness (3).

Sleep patterns vary across the life course (3), are affected by ageing processes (4) and have been associated with demographic and socio-economic characteristics (e.g. marital status, employment and parenthood) (1). Men and women exhibit differences in sleep-wake patterns which vary with age (3).

10 For example, on average, men have a more pronounced later chronotype (evening preference) than

11 women, especially in early adulthood, but this observed difference diminishes over time (5).

13 Sleep problems have been strongly associated with occupational accidents (6) and loss of productivity

14 (7), as well as elevated risk of cardiovascular disease (8), metabolic disease $(9,10)$, depression (11) and

15 some forms of cancer (12). The discordance in sleep patterns between cohabiting couples could

16 exacerbate sleep problems which may have social, psychological, and physical health implications (13).

18 Spousal concordance is well established in humans for several characteristics (14), including

19 cardiometabolic health (15), smoking (15), alcohol consumption (16), educational level (17), language

20 and culture (18). Spouses tend to be positively correlated for most measures phenotypes, and this may

21 represent positive assortative mating or social homogamy (whereby individuals select phenotypically

22 similar partners), interactions after partnership (where an individual's behaviour influences that of their

23 spouse) which may result in convergence over time, or confounding by shared environmental factors

24 (19). It is plausible that sleep traits between spouses may also be influenced by these processes.

26 In a study of 46 couples, actigraphy-assessed sleep movements were more frequent when couples were

27 sleeping together versus when sleeping apart (6\% vs 5.5\% probability of movement onset per hour

28 asleep), and yet subjective sleep was generally reported to be worse when sleeping apart (44\% reported

29 sleeping better with their partner present vs. $22 \%$ when their partner was away) (20). The same study

30 found that females reported being disturbed more often by their partner than was the case for males

31 (9\% vs. 6\%). Another study of 36 couples evaluated the interdependence of sleeping patterns based on

32 several actigraphy-assessed measures and found strong correlations in bed time (intraclass correlation 
medRxiv preprint doi: https://doi.org/10.1101/2022.01.13.22269233; this version posted January 13, 2022. The copyright holder for this preprint (which was not certified by peer review) is the author/funder, who has granted medRxiv a license to display the preprint in perpetuity.

It is made available under a CC-BY 4.0 International license .

$33(\mathrm{ICC})=0.42 ; \mathrm{p}<0.01)$, sleep latency $(\mathrm{ICC}=0.25, \mathrm{p}<0.001)$, light $/$ dark ratio $(\mathrm{ICC}=0.28, \mathrm{p}<0.001)$ and wake

34 bouts (ICC $=0.42 ; p<0.001)$ between couples $(21)$.

Previous studies using actigraphy measures to investigate spousal sleeping patterns have been limited in

37 terms of sample size. While larger studies have investigated self-reported sleep traits among spouses

38 (22, 23), they may suffer from bias due to individuals' perception and recall of sleeping patterns, which

39 may differ between men and women. Previous observational studies investigating both self-reported

40 and objectively-assessed sleeping patterns between spouses may also be biased by confounding (i.e. by

41 shared socioeconomic and lifestyle factors) and it can be difficult to determine the directionality in

42 correlated sleep patterns between spouses (i.e. the extent to which one spouse influences the sleep

43 patterns of the other, and vice versa).

Mendelian randomization (MR) is a method that uses genetic variants to evaluate causality between two traits by minimizing risk of confounding and reverse causation (24-26). While it is typically used to investigate effects of traits within the same individual, it may be extended to investigate the effect of one individual on another (27). This builds on the concept of "social" or "indirect" genetic effects (2831), where the genotype of an individual influences the phenotype of an individual's contacts (spouses, parents or friends). Evidence for indirect genetic effects between couples across a range of socioeconomic, lifestyle and behavioural phenotypes has been recently identified in large-scale population datasets $(32,33)$. One study used genetic data from cohabiting spouses in UK Biobank to investigate the possible causes of spousal similarity for alcohol behaviour (34). A similar approach can be used to

54 investigate spousal correlation in sleep behaviour.

Accelerometer-based assessment of sleep patterns, which have been demonstrated to be correlated with gold-standard polysomnography data (35), are now available in much larger studies such as the UK Biobank (36). The UK Biobank also has data on self-reported sleep traits, as well as genetic data, and contains $\sim 50,000$ cohabiting spouses (34). In this study, we aimed to investigate similarities in sleeping patterns between spouses in UK Biobank

62 and 23 andMe, Inc. ( $n=174,455$ spouse-pairs). If similarities in sleeping patterns and circadian preference

63 are observed, this may represent assortative mating by sleep traits, sleep interactions after partnership

64 (where an individual's sleep pattern influences that of their spouse's) or confounding by shared 
envirtvionmental factors (Figure 1). To minimize risk of confounding, we performed MR using genetic variants associated with the nine sleep traits to estimate the effect of an individual's sleep patterns on those of their spouse. To determine whether any effects represent assortative mating, we also investigated genetic concordance for sleep traits between spouses, which would imply that an effect exists prior to pairing (since genotypes cannot be modified). Finally, we conducted sensitivity analyses to evaluate potential bias in the MR analysis.

\section{Results}

\section{UK Biobank}

Of the 47,549 derived spouse-pairs in the UK Biobank, 47,420 (99.7\%) had reported information about their sleep in a touchscreen questionnaire completed at baseline and 3,454 pairs (7.3\%) had valid data from a triaxial accelerometer device (Axivity AX3) worn for a continuous period of up to 7 days between 2.8 and 8.7 years after study baseline, from which several sleep measures were derived (Supplementary Figure 1, Box 1).

82 The mean age of female and male spouses at baseline was 56.8 (SD 7.3) and 58.5 (7.3) years,

83 respectively. Reported sleep duration was similar between both females and males (mean (SD): 7.3 (1.1)

84 and 7.2 (1.0) hours). Males were slightly more likely to report no chronotype preference (12.8\% males vs. $8.4 \%$ females) and to report an extreme evening preference ( $7.0 \%$ males vs $6.4 \%$ females), while females were slightly more likely to report an extreme morning preference ( $23.9 \%$ females vs $22.6 \%$ males). Male spouses found waking up in the morning easier, with $40.2 \%$ finding it very easy compared with $27.4 \%$ women. Female spouses reported more frequent insomnia symptoms, with $82.5 \%$ reporting to sometimes or usually have symptoms, compared with $69.6 \%$ of males. Males were more likely to say that their spouse complained about their snoring (53.6\% vs 30.2\%) (Table 1).

92 Of those spouse-pairs who participated in the accelerometer assessment, the mean age of females and 93 males was 63.1 (SD 6.9) and 64.8 (7.0) years when worn. Estimated nocturnal sleep duration was similar 94 between male and female spouses (7.5 (0.8) and $7.3(0.9)$ hours) and was consistent with the self-

95 reported estimates. Timing of the least active 5 hours the day (L5-timing) was equivalent between males 96 and females, with the mean midpoint estimated as 3.18am (SD 1.0). Despite reporting more frequent 
medRxiv preprint doi: https://doi.org/10.1101/2022.01.13.22269233; this version posted January 13, 2022. The copyright holder for this preprint (which was not certified by peer review) is the author/funder, who has granted medRxiv a license to display the preprint in perpetuity.

It is made available under a CC-BY 4.0 International license .

insomnia and difficulty getting up in the mornings at baseline, females who wore the accelerometer had more efficient sleep $(0.78(0.06)$ vs $0.75(0.07)$ with fewer sleep episodes (16.9 (3.5) vs $17.6(3.8))$ than their male spouses (Table $\mathbf{1}$ ).

The UK Biobank spouse-pairs were slightly older (mean age 57.6 years (7.4)) than the remainder of the UK Biobank cohort (56.3 years (8.2)), had a lower Townsend deprivation index (TDI) (mean -2.2 (2.5) vs. $1.1(3.2))$, were less likely to be current smokers (7.1\% vs. $11.4 \%)$ and more likely to abstain from alcohol (22.3\% vs $19.9 \%)$. However, they were less likely to be employed ( $54.3 \%$ vs $58.3 \%$ ) and to have a university degree (31.6\% vs 33.0\%) (Supplementary Table 1). Those individuals in spouse-pairs who participated in the accelerometer assessment had a lower TDI (mean -2.4 (2.3) vs -2.1 (2.5)) and were more likely to be employed (56.3\%) and to have a university degree (41.3\%) than those spouse-pairs who did not participate (53.8\% and $29.0 \%$ ). They also had a lower body mass index (BMI), were less likely to be current smokers ( $4.8 \%$ vs. $7.7 \%)$ and more likely to abstain from alcohol ( $24.0 \%$ vs $21.9 \%)$

\section{(Supplementary Table 2).}

72.4\% of the UK Biobank participants with genetic data reported living with a spouse. They were less likely to report having an extreme evening preference (7.2\%) compared with those living with someone other than a spouse (9.9\%) or living alone (10.7\%); found it less difficult waking up in the morning (3.2\% vs $6.0 \%$ and $5.6 \%)$ and experienced less frequent insomnia symptoms ( $27.1 \%$ vs $29.3 \%$ and $31.7 \%)$. They were more likely to report snoring ( $40.3 \%$ vs $28.9 \%$ and $27.1 \%$ ), which is likely an artefact of how this question was asked: "Does your partner or a close relative or friend complain about your snoring?". Both self-reported and accelerometer-derived sleep duration were similar between the household categories, as was accelerometer-derived diurnal activity (L5-timing), nocturnal sleep episodes and sleep efficiency. Findings were similar when stratified by sex, except for snoring behaviour which was reported at a similar prevalence among women in the different household categories (Supplementary Table 3). Sleep traits among participants who also had a spouse in the UK Biobank cohort (UK Biobank spouse-pairs) were generally similar to those who reported living with a spouse not in UK Biobank

\section{(Supplementary Table 1).}

\section{3andMe}

The mean age of female and male spouses in 23andMe was 62.5 (SD 11.5) and 64.5 (11.7), respectively. Reported sleep duration was similar between both females and males, but less than that reported in UK 
medRxiv preprint doi: https://doi.org/10.1101/2022.01.13.22269233; this version posted January 13, 2022. The copyright holder for this preprint (which was not certified by peer review) is the author/funder, who has granted medRxiv a license to display the preprint in perpetuity.

It is made available under a CC-BY 4.0 International license .

129 Biobank (mean (SD): 5.9 (1.2) and 5.9 (1.1) hours). Unlike in UK Biobank, males in 23andMe were less

130 likely to report having an evening preference than their spouses (34.5\% vs $41.7 \%$ ), Female spouses were 131 more likely to report having been diagnosed or treated with insomnia (20.0\% vs $11.9 \%)$. Male spouses

132 were more likely to report that they snored (56.7\% vs $37.2 \%$ ) (Supplementary Table 4).

134 Spousal phenotypic correlation for sleep traits

135 UK Biobank

136 Self-reported and accelerometer-derived sleep traits were correlated between spouse-pairs, except for 137 insomnia and snoring. Weak positive correlations were found for $\mathrm{L} 5$-timing $(r=0.24 ; 95 \% \mathrm{Cl}=0.21,0.27)$, 138 self-reported and accelerometer-derived sleep duration $(r=0.11 ; 0.10,0.12$ and $r=0.12 ; 0.09,0.15$, 139 respectively), sleep efficiency $(r=0.07 ; 0.04,0.10)$, number of sleep episodes $(r=0.08 ; 0.05,0.11)$ and 140 ease of waking $(r=0.04 ; 0.04,0.05)$. An inverse correlation was observed for chronotype $(r=-0.11 ;-0.12,-$

1410.10 ) (Figure 2). Phenotypic correlations were generally smaller in magnitude than other

142 sociodemographic and lifestyle factors considered, which were all positive correlated between spouses

143 ( $r=0.13$ ?to 0.47) (Figure 2). Corresponding risk and mean differences obtained from multivariable (MV)

144 regression were very similar to the phenotypic correlations (as expected given that MV regression of SD 145 on SD partial correlation) (Table 2). Weak cross-trait correlations were also evident between the 146 spouses, with the largest positive correlation between snoring and insomnia $(r=0.10 ; 0.09,0.11)$ and the 147 largest inverse correlation between L5-timing (later diurnal activity) and chronotype (morning 148 preference) ( $r=-0.07 ;-0.09,-0.05)$ (Supplementary Figure 2).

\section{3andMe}

151 Self-reported sleep traits were also correlated between spouse-pairs in 23andMe (Supplementary Table 152 3). Similar to UK Biobank, sleep duration was positively correlated between spouses $(r=0.12 ; 0.09,0.15)$ 153 while chronotype was inversely correlated ( $r=-0.13 ;-0.14,-0.12)$ (Figure 2 ). Weak positive correlations 154 were also observed for insomnia ( $r=0.07 ; 0.06,0.07)$ and snoring $(r=0.05 ; 0.03,0.07)$, which were larger 155 in magnitude than in UK Biobank (Figure 3). Again, weak cross-trait correlations were observed between 156 spouses, with the largest positive correlation between insomnia and snoring ( $r=0.07 ; 0.05,0.09)$, and the 157 largest inverse correlation between sleep duration and snoring ( $r=-0.06 ;-0.10,-0.02)$ (Supplementary 158 Figure 3). 
medRxiv preprint doi: https://doi.org/10.1101/2022.01.13.22269233; this version posted January 13, 2022. The copyright holder for this preprint (which was not certified by peer review) is the author/funder, who has granted medRxiv a license to display the preprint in perpetuity.

It is made available under a CC-BY 4.0 International license .

161 In the UK Biobank, genetic risk scores (GRS) for each of the self-reported and accelerometer-derived 162 sleep traits were generated based on single nucleotide polymorphisms (SNPs) surpassing genome-wide 163 significance $\left(p<5 \times 10^{-8}\right)$ in previous genome-wide association studies (GWAS) (see Methods). Details of 164 the number of SNPS contributing to the GRS and the variation explained in the sleep traits by the GRS in

165 female and male spouses are shown in Table 3. The GRS explained between 0.1 and $1.4 \%$ of the variance 166 in the respective sleep traits, conferring adequate genetic instrument strength for the self-reported 167 sleep traits (F-statistics 132-604), although the variance explained differed between males and female 168 spouses for the accelerometer-derived sleep traits and there was an indication of weak instruments $169(\mathrm{~F}<10)$ for sleep efficiency and L5-timing in females (F-statistics 4.8 and 8.5, respectively).

171 MR effect estimates from two-stage least squares (2SLS) analysis were largely consistent with those

172 from MV regression (Table 2), with the exception of snoring, where MR estimated a larger inverse effect 173 between spouses ( $r$ isk difference $=-0.15 ;-0.27,-0.04 ; p$-value for difference from MV estimate $=0.017$ ).

174 We observed that participants' chronotype was more likely to induce the opposite chronotype in their 175 spouse (mean difference=-0.15; -0.26, -0.04 SD per SD). Longer sleep duration of one spouse was 176 positively related to sleep duration in the other $(0.13 ; 0.04,0.23$ SD per SD). From the accelerometer 177 assessment, activity timing was positively related between spouses in MR analysis (mean difference: $1780.49 ; 0.03,0.94$ SD per SD) and there were consistent estimates for the effect of sleep duration, albeit 179 with wider confidence intervals than the self-reported equivalent $(0.13 ;-0.12,0.39$ SD per SD).

181 When the impact of male spouses' sleep was separated from female spouses' sleep, effect estimates 182 were similar for the majority of sleep traits, with a few exceptions. Males' chronotype had a stronger 183 inverse effect on the chronotype of female spouses, while females' ease of waking had a stronger inverse effect on ease of waking of male spouses (Supplementary Figure 4).

186 In addition to investigating causal estimates for one given sleep trait between spouses, we also 187 examined cross-trait effects using MR (Supplementary Figure 5). The directions of association between 188 the spousal sleep traits were relatively consistent with those observed from the spousal phenotypic 189 correlations (Supplementary Figure 2). The strongest cross-traits effects were seen for the diurnal 190 preference traits (ease of waking and chronotype), where easier waking was inversely related to 191 spouses' report of morning preference (mean difference $=-0.15 ; 0.25,-0.06$ SD per SD) and reciprocally, 
medRxiv preprint doi: https://doi.org/10.1101/2022.01.13.22269233; this version posted January 13, 2022. The copyright holder for this preprint (which was not certified by peer review) is the author/funder, who has granted medRxiv a license to display the preprint in perpetuity.

It is made available under a CC-BY 4.0 International license .

192 morning preference was inversely related to spouses' ease of waking (mean difference $=-0.08 ; 0.14$, -

1930.01 SD per SD). However, the opposite direction of effect was observed for diurnal preference on

194 spouses' diurnal activity, where later L5-timing was inversely related to spouses' ease of waking (mean

195 difference=-0.30; 0.60, 0.00 SD per SD). Insomnia was also found to have a causal positive effect on

196 spouses' reported snoring (mean difference=0.10; 0.04, 0.16 SD per SD), but not vice versa (risk

197 difference $=-0.02 ;-0.05,0.01)$. This implies that an individual with insomnia is more likely to report their

198 spouses' snoring.

200 Genetic risk score correlation

201 There was limited evidence for genotypic correlations between the sleep traits as determined based on

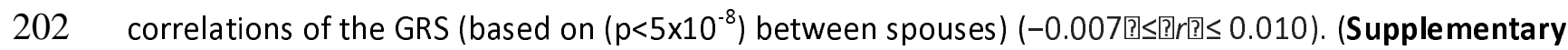

203 Figure 6). Cross-trait correlations between the GRS were also less evident $(-0.009$ [?] $[n] \leq 0.006)$.

204 Findings were similar when using a series of additional GRS derived from SNPs selected at a lower $p$ 205 value threshold from the GWAS for each sleep trait $\left(p<5 \times 10^{-7}, p<5 \times 10^{-6}\right.$ and $\left.p<5 \times 10^{-5}\right)$ (Supplementary

206 Figure 7). The only trait demonstrating consistent (but weak) evidence of correlation between the 207 spouses was for insomnia $(0.009$ [?] $[r$ ? $\leq 0.014)$.

Difference in effects by age, time of wear and birth location

210 For those sleep traits where we found evidence suggestive of effects between spouses, we investigated

211 whether the effects were modified by age, birth location and time of wear characteristics. Effect

212 modification by age was assessed as a proxy for relationship length, whereby evidence of stronger

213 effects with longer relationships could provide more evidence for convergence in behaviours after

214 partnership. We assessed whether effects varied by birth location of the spouses to evaluate potential

215 confounding by population structure (i.e. where spouses originating from similar areas may be more

216 similar to each other than those born further apart). Finally, given variation in the dates when the

217 accelerometer was worn by UK Biobank participants, we also investigated whether spousal effects for

218 the accelerometer-derived traits varied by differences in season and date of wear between the spouses.

220 Analysis stratified by age and birth location revealed limited evidence for heterogeneity in effects 221 estimates for chronotype $\left(I^{2}=0 \%\right.$, PHet $\left.\geq 0.45\right)$. Moderate heterogeneity by mean age was observed for 222 sleep duration $\left(I^{2}=62 \%\right.$, PHet=0.07) with larger effects at older ages (mean differences $=-0.02 ;-0.18,0.13$

223 SD per SD for 40-54 years; 0.17; 0.05, 0.39 SD per SD for 55-61 years; 0.22; 0.07, 0.36 SD per SD for 62- 
medRxiv preprint doi: https://doi.org/10.1101/2022.01.13.22269233; this version posted January 13, 2022. The copyright holder for this preprint (which was not certified by peer review) is the author/funder, who has granted medRxiv a license to display the preprint in perpetuity.

It is made available under a CC-BY 4.0 International license .

22470 years $)$. There was also moderate heterogeneity by age difference for snoring $\left(\mathrm{I}^{2}=61 \%\right.$, PHet $\left.=0.07\right)$ but

225 no linear trend was observed. Analysis stratified by age, birth location and time/season of wear for the 226 accelerometer assessment revealed limited evidence for heterogeneity in effect estimates for L5-timing

$227 \quad\left(I^{2} \leq 23 \%\right.$, PHet $\left.\geq 0.26\right)$ (Supplementary Figure 8).

228

229 Robustness of MR analyses: Horizontal pleiotropy

230 For those sleep traits where there was an indicated effect between spouses, we found little evidence for

231 horizontal pleiotropy based on: i) a Sargan test which evaluates between-SNP heterogeneity in the

232 causal estimates (Supplementary Table 6) and ii) an MR-Egger intercept test which tests for directional

233 pleiotropy (Supplementary Table 6). We also evaluated effect estimates using methods which can

234 account for pleiotropy in this setting (37). Effect estimates were largely consistent in direction with

235 those obtained from both MV and 2SLS analysis, although with wider confidence intervals for the MR-

236 Egger and Least Absolute Deviation (LAD) approaches, which crossed the null (Figure 4, Supplementary

237 Table 7). However, mean F-statistics and $I^{2}$ values for the individual SNP-exposure estimates used in

238 these analyses were found to be small, indicating presence of weak genetic instruments

239 (Supplementary Table 6). Together, findings suggest that our main results are likely robust to horizontal

240 pleiotropy, although the presence of weak instruments indicates that this sensitivity analysis should be

241 interpreted with caution.

243 Robustness of MR analyses: Winner's curse

244 We derived GRS comprising a subset of SNPs used in the main analysis which replicated in independent

245 datasets in order to evaluate potential Winner's curse. This could be present due to overlap between

246 the sleep GWAS and spouse-pair sample, leading to an overestimation of the individual SNP effects on

247 the exposure. Effect estimates for chronotype and sleep duration using replicated SNPs were largely

248 consistent with those from the main analysis (Supplementary Table 8). For insomnia, the effect

249 estimates obtained based on SNPs which replicated in 23andMe were more consistent with a positive

250 effect between spouses $(0.173 ;-0.025,0.371)$, with estimates in the opposite direction to those

251 obtained in the main analysis from UK Biobank (-0.046, -0.151, 0.058) (Supplementary Table 8). We also

252 re-estimated effects for insomnia using SNPs identified in a meta-analysis of UK Biobank and 23andMe

253 (38). Estimates were also in the opposite direction to the main analysis although still consistent with the

254 null $(0.076,-0.025,0.177)$ (Supplementary Table 9) 
medRxiv preprint doi: https://doi.org/10.1101/2022.01.13.22269233; this version posted January 13, 2022. The copyright holder for this preprint (which was not certified by peer review) is the author/funder, who has granted medRxiv a license to display the preprint in perpetuity.

It is made available under a CC-BY 4.0 International license .

\section{Discussion}

257 Using a sample of spouse-pairs within the UK Biobank study, we investigated the correlation in sleep

258 patterns and circadian preference between spouses using data on both self-reported and

259 accelerometer-derived sleep traits. We found evidence for weak positive phenotypic correlations

260 between spouses for sleep duration, ease of waking, timing of diurnal activity and number of nocturnal

261 sleep episodes as well as a weak inverse correlation between spouses for reported chronotype (diurnal

262 preference). Findings of a positive correlation for sleep duration and inverse correlation for chronotype

263 were replicated in 23 andMe. Several cross-trait correlations were also observed between spouses.

264 Individuals who reported having insomnia were more likely to report snoring by their spouse in both UK

265 Biobank and 23andMe. Additionally, morning preference in the index individual was associated with

266 later activity timing of their spouse in UK Biobank. In MR analyses, positive effects of sleep duration and

267 activity timing were found between spouses as well as inverse effects of chronotype and snoring on the

268 same traits in their partners. We were unable to determine whether males or females had more bearing

269 on their spouse's sleep patterns, and no large differences in effects were found by age, birth location,

270 and timing of the accelerometer assessment. This was except for sleep duration, where larger positive

271 effects were observed at older ages, suggesting a convergence in sleep duration between spouses over

272 time. GRS correlations in the sleep traits were weaker than phenotypic correlations between spouses,

273 providing some evidence against assortative mating (whereby individuals select phenotypically similar

274 partners).

276 In line with our findings, Randler and Kretz found correlations in several sleep-wake variables between

277 spouses (39). However, in contrast to the moderate positive relationship in chronotype observed in that

278 small study ( $r=0.40, n=84$ couples), weak inverse effects for chronotype were found between spouses in

279 the UK Biobank and 23andMe ( $r=-0.11$ and -0.13 , respectively), which was supported by MR analysis.

280 The inverse correlation is unexpected, especially given the positive correlation between accelerometer-

281 assessed L5-timing. This suggests a separation of subjective chronotype, reflective of diurnal preference,

282 from actual objective sleep timing. Inverse correlations also go against the plethora of evidence

283 indicating wide-spread similarities (rather than differences) of spouses for many phenotypes (Figure 2)

284 (33). However, it should be emphasised that the inverse correlation observed for chronotype was

285 relatively weak in both studies. 
medRxiv preprint doi: https://doi.org/10.1101/2022.01.13.22269233; this version posted January 13, 2022. The copyright holder for this preprint (which was not certified by peer review) is the author/funder, who has granted medRxiv a license to display the preprint in perpetuity.

It is made available under a CC-BY 4.0 International license .

287 Similar to our findings, the previous study did not find a correlation between length of relationship

288 (proxied in our study by mean age of couples) and dissimilarity in morning-evening preference (39). They

289 interpreted this as suggesting initial assortment by chronotype, whereas the lack of GRS correlation

290 ( $r=0.001)$ and discordance in chronotype between spouses does not provide the same evidence for

291 assortative mating in UK Biobank and 23andMe. Additionally, our findings suggest that activity timing, as

292 proxied by accelerometer-assessed L5-timing in UK Biobank, converges between spouses and so may

293 deviate from reported diurnal preference after partnership.

295 The literature regarding insomnia between spouses is less consistent, with some studies reporting a

296 protective effect on insomnia symptoms of being in a partnership (3) and others showing more frequent

297 wake transmissions among partners of individuals with insomnia (40). Another study found that while

298 actigraphy-assessed sleep movements were greater when couples were sleeping together, subjective

299 sleep was generally reported to be worse when sleeping apart (20). We did not find a strong correlation

300 of insomnia symptoms between spouses, assessed based on self-report as well as accelerometer

301 measures of sleep efficiency and number of nocturnal sleep episodes. However, we did find some

302 evidence for an effect of sleep duration between spouses.

We also observed an inverse relationship between spouses' reported snoring, and a positive relationship

305 between snoring and insomnia in the spouse. Spouses of snorers have been found to more frequently

306 report sleeping problems including insomnia (23). However, the results of the MR analysis suggested

307 that this association may reflect a positive effect of an index individual's reported insomnia on snoring in

308 their spouse, rather than spouse's snoring inducing insomnia. This may be explained by the fact that

309 reported snoring is captured via the spouse of the snorer in the UK Biobank question, "Does your

310 partner or a close relative or friend complain about your snoring", and so if an individual experiences

311 insomnia symptoms, they may be more likely to notice and report snoring in their spouse.

313 Most of the studies which have investigated sleep correlations between spouses have done so in small,

314 cross-sectional settings, typically with fewer than a hundred couples $(20,21,39,40)$. The present study

315 uses data on 47,420 determined spouse-pairs within the UK Biobank to evaluate correlation in sleep

316 traits between spouses, with replication in 23andMe ( $n \leq 127,035$ spouse-pairs), as well as the use of

317 genetic analysis to evaluate causal effects underlying spousal correlation in sleep traits. Furthermore,

318 the availability of accelerometer data on $\sim 3,500$ couples in UK Biobank has enabled a comparison of 
medRxiv preprint doi: https://doi.org/10.1101/2022.01.13.22269233; this version posted January 13, 2022. The copyright holder for this preprint (which was not certified by peer review) is the author/funder, who has granted medRxiv a license to display the preprint in perpetuity.

It is made available under a CC-BY 4.0 International license .

319 both subjective reported sleep traits and objective sleep measures between spouses. Unlike findings

320 from a previous study which used a similar genetic approach in the UK Biobank to infer assortative

321 mating on both height and alcohol consumption (34), our finding of low GRS correlation between sleep

322 traits suggest that correlation for sleep traits did not exist prior to cohabitation but that spouses may

323 influence each other's sleep patterns after partnership.

325 The current study suffers from some limitations with respect to both the phenotypic measures and 326 genetic analysis which require discussion. We were unable to directly obtain information on spouses

327 within UK Biobank and instead spouses were inferred based on several criteria, including marital status

328 and location. Other studies have used similar methods to determine spouses and the validity of the

329 derived spouse-pair sample has been previously verified (34). In 23andMe, a different method was used

330 to infer spouse-pairs, based on genetic trios to obtain mother-father pairs. However, we could not

331 determine whether the 23andMe 'parents' were separated and not living together. We also did not

332 have information on whether couples in the UK Biobank or 23andMe shared a bed, and so we are

333 unable to determine the extent to which the effects observed are directly attributed to bed sharing

334 rather than cohabitation. Although the availability of accelerometer measures enabled an objective

335 assessment of sleep patterns between a large sample of spouses in the UK Biobank, individuals did not

336 wear an accelerometer at the same time as the self-reported assessment, with a median time difference

337 of 6 years between assessments for the spouses. Additionally, spouse-pairs wore the accelerometer 7

338 months apart on average, with only $4 \%$ of individuals wearing an accelerometer at the same time as

339 their spouse. While the results of our analysis suggest potential interactions after partnership which may

340 result in convergence of sleep traits over time, we were unable to investigate this longitudinally, which

341 would require repeat assessments of sleep traits. While we investigated effect modification by age, this

342 is a crude proxy measure for relationship length.

344 The use of MR allowed us to overcome problems of confounding and reverse causation has enabled an

345 assessment of the potentially causal relationship in sleep traits between spouses. While this offers

346 additional inference to phenotypic correlations, several other assumptions must be made in order for

347 the causal estimates to be valid (24-26). We have attempted to address and overcome most of these

348 assumptions, with assessments of instrument strength, population stratification, horizontal pleiotropy

349 and Winner's curse. Most robust inference can be made when the estimated effects are consistent in

350 sensitivity analyses which attempt to address these assumptions, which was the case for effects 
medRxiv preprint doi: https://doi.org/10.1101/2022.01.13.22269233; this version posted January 13, 2022. The copyright holder for this preprint (which was not certified by peer review) is the author/funder, who has granted medRxiv a license to display the preprint in perpetuity.

It is made available under a CC-BY 4.0 International license .

351 observed in relation to chronotype, diurnal behaviour and sleep duration. While the genetic instruments

352 were found to be strongly related to the sleep traits, for some of the accelerometer-derived traits, F-

353 statistics were small which could indicate weak instrument bias. This was particularly the case for

354 accelerometer traits in females, suggesting that there may be some sex differences in the genetic

355 contribution to the sleep traits. While we used GRS derived from SNPs identified in GWAS of men and

356 women combined, GRS comprising SNPs could be generated from sex-specific GWAS which may serve as

357 stronger instruments. However, there would be a necessary trade-off with lower sample sizes for the

358 sex-specific rather than sex-combined GWAS, which may reduce statistical power. Furthermore, mean

359 F-statistics of the individual SNP effects used in the analyses accounting for pleiotropy were found to be

360 small. However, the effects using the inverse-variance weighted approach were very consistent with

361 those obtained using the stronger GRS instrument in 2SLS analysis, indicating that this bias is unlikely to

362 be a major contributing factor.

364 We found that the spouse-pairs in UK Biobank differed in several socio-demographic characteristics

365 from the remainder of the UK Biobank cohort (including those participants who reported living with a

366 spouse but whose spouse was not in the study). While these differences were marginal, they suggest

367 that the spouse-pairs, particularly those with accelerometer data, were healthier and more affluent

368 which may influence the generalisability of findings to the full cohort. The UK Biobank and 23andMe

369 spouse-pairs are also unlikely to be fully representative of the general population, being more highly

370 educated, more affluent and in better health on average (41). Additionally, the mean ages of the

371 spouses in both studies were 57 and 63 years old, and so the findings regarding the correlation in

372 sleeping patterns and circadian preferences between spouses may not necessarily extrapolate to

373 younger couples, particularly those with contrasting work schedules. Furthermore, factors influencing

374 selection into the UK Biobank and 23andMe (42), and spousal assortment on other traits (19), may bias

375 spousal comparisons in both observational and MR analysis. However, previous simulations have

376 suggested that this most likely results in bias towards the null, leading to an under-estimate of the true

377 effect.

378

379 Another selection factor which could have biased estimates in the present study is relationship

380 dissolution, whereby sleep concordance/discordance could influence the likelihood of remaining in a

381 relationship and of participating in the UK Biobank study together. The lack of evidence to suggest that

382 mean age of each spouse-pair (as a proxy for relationship length) was associated with sleep correlation 
medRxiv preprint doi: https://doi.org/10.1101/2022.01.13.22269233; this version posted January 13, 2022. The copyright holder for this preprint (which was not certified by peer review) is the author/funder, who has granted medRxiv a license to display the preprint in perpetuity.

It is made available under a CC-BY 4.0 International license .

383 suggests that the effects observed are unlikely to be due to relationship dissolution. However, further

384 work is required to investigate whether similarities/dissimilarities in spousal sleep traits are predictive of 385 relationship dissolution (43).

Within two large population-based resources comprising a high proportion of spouse-pairs, we established correlations between several sleep traits between spouses. Within the UK Biobank, we were also able to evaluate accelerometer-based sleep assessment and used a genetic analysis to demonstrate effects of an individuals' sleep traits on those of their spouse for chronotype, diurnal activity, sleep

391 duration and snoring. Weak cross-trait associations were also evident in the study. Our results suggest

392 that these effects may be due to interaction after partnership rather than confounding by social

393 homogamy or assortative mating. According to the US National Sleep Foundation, $61 \%$ of adults sleep in

394 a bed with a significant other and 77\% of those who are married or co-habiting report that their partner 395 experienced sleep problems (44). Our findings indicate that this may have consequences for the sleep of

396 both spouses since sleep disruption has been implicated in a number of chronic diseases $(8,9,11,12)$.

397 However, the magnitude of sleep effects was small and whether this level of correlation between

398 spouses contributes towards disease risk, as indicated in (45), requires further investigation.

Methods

401 UK Biobank

402 The UK Biobank is a population-based cohort study consisting of $>500,000$ participants, aged between

40340 and 70 years, who were recruited between 2006 and 2010 in the UK (46). At recruitment, the 404 participants gave informed consent to participate and be followed up. UK Biobank has received ethical

405 approval from the UK National Health Service's National Research Ethics Service (ref 11/ NW/0382).

\section{Genetic data}

408 The full data release in UK Biobank contains the cohort of successfully genotyped individuals ( $\mathrm{N}=$

$409488,377)$. A total of 49,979 individuals were genotyped using the UK BiLEVE array and 438,398 using the

410 UK Biobank axiom array. Pre-imputation quality control, phasing and imputation of the UK Biobank

411 genetic data have been described elsewhere (47). We restricted the dataset to a subset of 463,827

412 individuals of recent European descent with available genotype data, with individuals of non-European

413 descent removed based on a k-means cluster analysis on the first four genetic PCs (48). 
medRxiv preprint doi: https://doi.org/10.1101/2022.01.13.22269233; this version posted January 13, 2022. The copyright holder for this preprint (which was not certified by peer review) is the author/funder, who has granted medRxiv a license to display the preprint in perpetuity.

It is made available under a CC-BY 4.0 International license .

\section{5}

416

417

418

419

420

421

422

423

424

425

426

427

428

429

430

\section{Household composition}

At baseline assessment, participants were asked to report the number of people living in their household (including themselves). For those who reported more than one person, they were asked how the other people were related to themselves, or whether they were unrelated. Using this information, we determined three groups of participants: living with spouse, living with someone other than spouse, living alone.

\section{Spouse-pair sub-sample}

Using the European sub-sample, spouse-pair information was determined using the same approach described previously (34). In brief, household sharing information was used to extract pairs of individuals who a) report living with their spouse, b) report the same length of time living in the house, c) report the same number of occupants in the household, d) report the same number of vehicles, e) report the same accommodation type and rental status, $f$ ) have identical home coordinates (to the nearest $1 \mathrm{~km}$ ) and $\mathrm{g}$ ) are registered to the same UK Biobank recruitment centre and $\mathrm{h}$ ) both have available genotype data. Exclusions were made if more than two individuals shared identical information across all variables (and so spouses could not be clearly defined), if potential couples who were the same sex (as our analysis was related to sex differences in sleep patterns and hence effects in heterosexual couples), if couples reported the same age of death for both parents (suggesting they were siblings rather than spouses), and if estimated genetic relatedness was deemed to be too high (identifyby-descent (IBD) $>0.1$, suggesting siblings or parent-child pairs rather than spouses). The final sample included 47,549 spouse-pairs.

\section{Sleep questionnaire measures}

At baseline assessment, participants were given a touchscreen questionnaire, which included questions about sociodemographic status, lifestyle and environment, early life and family history, health and medical history, and psychosocial factors. This included several questions related to sleep and circadian traits (Box 1).

We assessed spousal correlations between 5 self-reported sleep traits: chronotype (morning/evening preference), ease of waking up, insomnia symptoms, sleep duration and snoring. Chronotype was coded into five categories ("Definitely an 'evening' person”, "More an 'evening' than a 'morning' person”, “Do not know”, “More a 'morning' than 'evening' person”, “Definitely a 'morning' person”); ease of waking 
medRxiv preprint doi: https://doi.org/10.1101/2022.01.13.22269233; this version posted January 13, 2022. The copyright holder for this preprint (which was not certified by peer review) is the author/funder, who has granted medRxiv a license to display the preprint in perpetuity.

It is made available under a CC-BY 4.0 International license .

447 was coded into four categories ("Not at all easy", "Not very easy", "Fairly easy", "Very easy"); total 24-

448 hour sleep duration was reported in whole hours; insomnia symptoms frequency was coded into three

449 categories ("Never/rarely", "Sometimes", "Usually") and snoring was coded as a binary variable ("No" or

450 "Yes"). Those who responded "Do not know" or "Prefer not to say" were treated as missing data for all

451 sleep traits, except for chronotype where "Do not know" was treated as an intermediate category. A

452 binary was also generated for chronotype ("Evening vs Morning person"), by combining definite and

453 intermediate categories, and excluding those who reported "Do not know", as well as for insomnia, by

454 combining "Never/rarely" and "Sometimes"). This was done to aid comparison with findings from

455 23andMe.

Accelerometer measures

458 A triaxial accelerometer device (Axivity AX3 was worn between 2.8 and 8.7 years after study baseline by

459103,711 individuals from the UK Biobank for a continuous period of up to 7 days. Details of data

460 collection and processing have been previously described (49). Measures of sleep quality, quantity and

461 timing have been derived by processing raw accelerometer data with use of the open-source R package

462 GGIR (50). More details on the accelerometer-based sleep measures derived in UK Biobank can be found

463 in (51). These have been returned to UK Biobank as part of data return 1862.

We investigated four continuous measures: mean L5 time (midpoint of least-active 5 hours), mean number of nocturnal sleep episodes, mean daily sleep duration and mean sleep efficiency. The least-

467 active five hours (L5) of each day was derived using a five-hour period of minimum activity. This period

468 was estimated using a rolling average of the respective time window and defined as the number of

469 hours elapsed from the previous midnight. The sleep period time (SPT)-window was estimated using an

470 algorithm described in (52). The number of sleep episodes within the SPT-window was defined as the

471 number of sleep bouts separated by at least 5 minutes of wakefulness within the SPT-window. The

472 summed duration of all sleep episodes was used as an indicator of sleep duration within the SPT-

473 window. Sleep efficiency was calculated as sleep duration divided by SPT-window duration.

475 We excluded individuals flagged by UK Biobank as having data problems (field 90002), poor wear time

476 (field 90015), poor calibration (field 90016), or unable to calibrate activity data on the device worn itself

477 requiring the use of other data (field 90017). Individuals were also excluded if the number of data

478 recording errors (field 90182), interrupted recording periods (field 90180), or duration of interrupted 
medRxiv preprint doi: https://doi.org/10.1101/2022.01.13.22269233; this version posted January 13, 2022. The copyright holder for this preprint (which was not certified by peer review) is the author/funder, who has granted medRxiv a license to display the preprint in perpetuity.

It is made available under a CC-BY 4.0 International license .

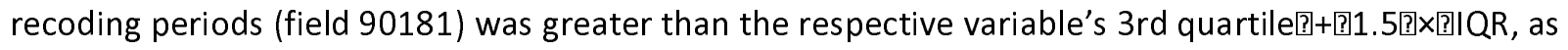

480 previously reported (51).

\section{Covariates}

483 The age of the participants at the baseline assessment (when self-reported measures were obtained)

484 were derived based on date of birth and the date of attending the assessment centre. Age at

485 accelerometry assessment was estimated using date of birth and the date of the first recording day. Sex

486 was determined at recruitment and individuals with sex-mismatch (derived by comparing genetic sex

487 and reported sex) ( $n=378$ ) or individuals with sex-chromosome aneuploidy ( $n=652)$ were excluded from

488 the analysis. Information on which of the 22 centres in Scotland, England and Wales where assessments

489 were undertaken was also obtained. Place of birth in the UK was ascertained from a verbal interview at

490 the assessment centre and UK Grid co-ordinates (north and east) were determined. Season when the

491 accelerometer was worn was also ascertained. For all genetic analysis, we also included genotyping chip

492 and the top 10 PCs derived from the genetic data as covariates.

\section{23andMe}

495 Individuals in the 23andMe dataset were customers of 23andMe, Inc., a personal genomics company.

496 Participants provided informed consent and participated in the research online, under a protocol

497 approved by the external AAHRPP-accredited IRB, Ethical \& Independent Review Services (E\&I Review).

498 Participants were included in the analysis on the basis of consent status as checked at the time data

499 analyses were initiated.

\section{Spouse-pair sub-sample}

502 Parent-offspring trios were identified from the 23andMe database using identity-by-descent (IBD)

503 information. Specifically, a segment-based approach was used to designate IBD1 and IBD2,

504 corresponding to regions that have the indicated number (one or two) of shared haplotypes between

505 two individuals. Every individual was considered as a potential child in a trio (called index individual),

506 and candidate parents were identified as those sharing at least $42.5 \%$ of their genome IBD1 and no

507 more than $10 \%$ of their genome IBD2 with the index individual. Genome-wide relatedness between

508 pairs of candidate parents was then computed to eliminate incorrect candidate pairs (for example,

509 where one candidate parent is a true parent of the index individual and the other candidate parent is a

510 child of the index individual) by requiring candidate parents to share no more than $20 \%$ of their genome 
medRxiv preprint doi: https://doi.org/10.1101/2022.01.13.22269233; this version posted January 13, 2022. The copyright holder for this preprint (which was not certified by peer review) is the author/funder, who has granted medRxiv a license to display the preprint in perpetuity.

It is made available under a CC-BY 4.0 International license .

511 IBD1 with each other. Lastly, trios were checked for mendelian concordance on 100 random SNPs with

512 genotyping rate $99.9 \%$ and $\mathrm{MAF}>0.3$, and were required to be concordant on at least 95 of the 100

513 tested SNPs.

514

515 From 771,487 parent-offspring trios in the 23andMe research cohort, children were removed to obtain

516 mother-father pairs. The trios were subsetted to 531,856 pairs, where both parents had complete data

517 for the sleep trait, age and sex, and were of predominantly European ancestry. A detailed description of

518 23andMe ancestry classifier can be found here $(53,54)$ where participants defined as predominantly

519 European ancestry were those who, after 23andMe ancestry composition, had a probability of European

$520+$ Middle Eastern ancestry $>0.97 \%$ or European ancestry $>0.90 \%$.

\section{Sleep questionnaire measures}

523 As part of the personal genomics service, all customers are invited to participate in research, which

524 occurs predominantly through web-based research surveys. Participants are asked a number of

525 questions about their sleep habits.

527 We assessed spousal correlations between 4 self-reported sleep traits: chronotype (morning/evening 528 preference), insomnia symptoms, sleep duration and snoring. Research participants were asked, "Are 529 you naturally a night person or a morning person?", with options "Night person", "Morning person", 530 "Neither", "It depends" and "I'm not sure". A binary variable was generated as "Morning person" vs 531 "Night person", where "It depends" and "I'm not sure" were treated as missing data. Participants also 532 answered the question, "Have you ever been diagnosed with, or treated for, insomnia?" with options 533 "Yes", "No", and "I'm not sure". A binary variable was generated as "Yes" vs "No", where "I'm not sure" 534 was treated as missing data. Participants were next asked, "During the past month, how many hours of 535 actual sleep did you get at night? (This may be different than the number of hours you spend in bed.)"

536 Responses were integers, with extreme responses of less than 3 hours or more than 12 hours excluded.

537 Finally, participants responded to the question, "On most nights, do you snore", with options "Yes",

538 "No" and "I'm not sure". A binary variable was generated as "Yes" vs "No", where "I'm not sure" was 539 treated as missing data. 
medRxiv preprint doi: https://doi.org/10.1101/2022.01.13.22269233; this version posted January 13, 2022. The copyright holder for this preprint (which was not certified by peer review) is the author/funder, who has granted medRxiv a license to display the preprint in perpetuity.

It is made available under a CC-BY 4.0 International license .

\section{Covariates}

542 Accompanying surveys provide self-reported data on covariates such as age and sex. Ancestry

543 composition was performed as previously reported (54). Inclusion was restricted to individuals of

544 predominantly European ancestry to minimize confounding by ancestry.

546 Statistical analysis

548 Phenotypic correlations in sleep traits between spouses were calculated in both UK Biobank and

549 23andMe, while the remainder of the analysis involved participants from UK Biobank only (MR and

550 Supplementary analysis).

\section{Spousal phenotypic correlation for sleep}

\section{UK Biobank}

554 To evaluate the phenotypic correlation of sleep traits, we compared self-reported sleep traits and

555 accelerometer measures between spouses. We estimated the spousal correlation for the 5 self-reported

556 sleep traits and 4 accelerometer-based sleep traits by assessing the correlation between the relevant

557 variable for an individual against the relevant variable for their spouse, using a Pearson correlation test

558 adjusting for age, spouse's age and recruitment centre. With one unique phenotype pairing within

559 couples (male sleep trait / female sleep trait), each individual in the dataset was included only once as

560 either the reference individual or their spouse. To contextualise the findings, we also calculated the

561 correlation between spouses for height (field 12144), body mass index (field 21001), smoking status

562 (field 20116), alcohol intake (field 1558), physical activity (field 894), employment status (field 6142) and

563 education level (field 6138), obtained at baseline assessment.

\section{3andMe}

566 To assess the spousal correlation for the 4 self-reported sleep traits, a regression of the sleep trait on

567 age was first performed and then the residuals extracted for each parent. A Pearson correlation test for

568 the age-corrected values was used to assess the correlation between the relevant variable for an

569 individual against the relevant variable for their spouse. With one unique phenotype pairing within

570 couples (male sleep trait / female sleep trait), each individual in the dataset was included only once as

571 either the reference individual or their spouse. 
medRxiv preprint doi: https://doi.org/10.1101/2022.01.13.22269233; this version posted January 13, 2022. The copyright holder for this preprint (which was not certified by peer review) is the author/funder, who has granted medRxiv a license to display the preprint in perpetuity.

It is made available under a CC-BY 4.0 International license .

\section{Mendelian Randomization analysis}

574 We used MR to investigate evidence for an effect of an individuals' sleeping patterns on the sleeping

575 patterns of their spouse. This was done by generating a series of genetic risk scores (GRS) for the 5 self-

576 reported sleep traits (chronotype (morning/evening preference)(55), ease of waking up, insomnia

577 symptoms (56), sleep duration (57) and snoring (58)) and 4 accelerometer-derived sleep traits (mean L5

578 time, number of nocturnal sleep episodes, mean daily sleep duration and mean sleep efficiency (36)).

579 Scores were generated based on single nucleotide polymorphisms (SNPs) surpassing genome-wide

580 significance $\left(p\right.$-value $<5 \times 10^{-8}$ ) in relation to the sleep traits in genome-wide association studies (GWAS)

$581(n=85,670-461,569)$. SNP lists were obtained from the relevant GWAS summary statistics available at

582 http://www.kp4cd.org/dataset_downloads/sleep. These were pruned for linkage disequilibrium

$583\left(r^{2}=0.001\right)$ based on a European reference panel, using the clump_data function from the

584 "TwoSampleMR" package in R (version 3.5.1) (59). Detailed information of the genetic variants is given

585 in Supplementary Table 10.

587 The genetic variants were extracted from the UK Biobank genetic data and unweighted GRS were

588 generated as the total number of sleep trait-increasing alleles (morning preference alleles for

589 chronotype) present in the genotype of each participant. Two-stage least squares (2SLS) instrumental

590 variable analyses were performed between standardized sleep traits (all traits with mean 0 and SD 1)

591 with adjustment for age at assessment, assessment centre, genotyping chip and 10 genetic principal

592 components (PCs) to minimize confounding by population stratification. This was performed using each

593 GRS as an instrument for its respective sleep traits using the "ivreg2" command in Stata (version 15).

595 Standardized variables are presented in the table to allow for direct comparisons with the correlation

596 coefficients estimated for the phenotypic correlation. To enable this, ordinal variables were treated

597 continuously. We also performed MV regression using the same variables with adjustment for age at

598 assessment and assessment centre, and performed a z-test for difference with the 2SLS estimate to

599 determine the extent to which the effects estimated from MR were consistent with the observational

600 associations.

601

602 With two unique pairings between genotype and sleep trait in each couple (male spouse

603 genotype/female spouse sleep trait and the converse), each individual in the dataset was included twice

604 as both the reference individual and as the spouse. This analysis was performed by sex (i.e. male spouse 
medRxiv preprint doi: https://doi.org/10.1101/2022.01.13.22269233; this version posted January 13, 2022. The copyright holder for this preprint (which was not certified by peer review) is the author/funder, who has granted medRxiv a license to display the preprint in perpetuity.

It is made available under a CC-BY 4.0 International license .

605 genotype/female spouse sleep trait and female spouse genotype/male spouse sleep trait) to evaluate

606 any differential effects between males and females on their spouses' sleep patterns and then combined

607 the estimates obtained using an inverse-variance weighted random effects meta-analysis.

608

609 Supplementary analysis

610

\section{Genetic risk score correlation}

612 We assessed the correlation between the sleep GRS across spouse-pairs, adjusting for age, spouse's age, 613 assessment centre, genotyping chip and top 10 PCs. With one unique genotype pairing within couples

614 (male spouse genotype/female spouse genotype), each individual in the dataset was included only once

615 as either the reference individual or their spouse. In sensitivity analysis, we also assess the spousal

616 correlation of three additional GRS for each sleep trait, derived using less stringent $p$-value thresholds

617 for selecting contributing SNPs $\left(p<5 \times 10^{-7}, p<5 \times 10^{-6}\right.$ and $\left.p<5 \times 10^{-5}\right)$.

\section{Difference in effects by age, time of wear and location}

620 Where a sleep trait was found to have an effect on the same sleep trait of the spouse, we investigated

621 the extent to which this estimate varied by mean age of the spouses, the difference in ages between the

622 spouses, the birth location of the spouses and, for any accelerometer measures, differences between

623 spouses in terms of the season of wear and the time difference in wear. We investigated whether

624 results differed by age, location, season and timing by repeating MR analyses in subgroups as follows:

625 (1) by thirds of the age distribution; (2) less or more than $100 \mathrm{~km}$ from where their spouse was born (34);

626 (3) whether the season of wearing the accelerometer differed between spouses (yes or no); (4) by thirds

627 of the difference in accelerometer wear-time between spouses. We meta-analysed estimates assuming

628 a fixed effects model using the meta package in $\mathrm{R}$ (version 3.5.1) to obtain an $\mathrm{I}^{2}$ value for heterogeneity.

630 Assessing MR assumptions and evaluating bias

631 MR analysis requires various assumptions to be satisfied in order for effects to be estimated: 1) that the

632 genetic instrument is robustly associated with the exposure (instrument strength); 2) that the genetic

633 instrument is independent of potential confounders of the exposure-outcome association (no

634 confounding) and 3) that the genetic instrument influences the outcome exclusively through its effect

635 on the exposure (no horizontal pleiotropy). Various steps were taken to assess these assumptions, as

636 outlined below. 
medRxiv preprint doi: https://doi.org/10.1101/2022.01.13.22269233; this version posted January 13, 2022. The copyright holder for this preprint (which was not certified by peer review) is the author/funder, who has granted medRxiv a license to display the preprint in perpetuity.

It is made available under a CC-BY 4.0 International license .

638 Partial $r^{2}$ values and F-statistics from the first-stage regression between each GRS and the index

639 individuals' sleep traits were examined to check adequate instrument strength.

641 While genetic variants should not theoretically be related to potential confounding factors, concerns

642 about potential violation of this assumption relate to confounding by ancestry or population

643 stratification, including assortative mating effects. To address this, we adjusted for principal components

644 derived from the genetic data in the MR analysis in order to control for population structure. The

645 sensitivity analysis examining spousal correlation by geographic birth proximity was also used to

646 evaluate potential confounding by social homogamy. We also examined the influence of assortative

647 mating by evaluating GRS correlation of the sleep traits, as described above.

649 Horizontal pleiotropy, where genetic variants may influence the outcome of interest through pathways

650 other than via the exposure, is an important limitation in conventional MR analysis. However, in the

651 context of spousal effects, pleiotropy of the genetic variants is arguably less problematic since there are

652 unlikely to be biological mechanisms by which an individual's genotype could plausibly affect their

653 spouses' phenotypes other than via the observed phenotype. Nonetheless, there may be other (e.g.

654 social) mechanisms which give rise to pleiotropy of the variants, and so we have conducted sensitivity

655 analyses to evaluate this.

657 To assess bias due to horizontal pleiotropy, we first explored between-SNP heterogeneity using the

658 Sargan over-identification test. We also applied a method that estimates unbalanced horizontal

659 pleiotropy in a one-sample MR setting (37). This method provides causal estimates using methods which

660 have been adapted from the two-sample MR setting, including inverse-variance weighted (IVW) meta-

661 analysis (60), MR-Egger (61) and least absolute deviation (LAD) regression (similar to the weighted

662 median approach (62)). More details of these methods are described in (37).

664 Winner's curse can occur when the study in which the genetic variants were identified at genome-wide 665 significance $\left(p<5 \times 10^{-8}\right)$ is the same as the one used to perform the MR analysis. Since the genetic

666 variants for the sleep traits were predominantly identified in UK Biobank, this may bias causal estimates 667 towards the null. To minimize the impact of Winner's curse, we used unweighted GRSs in the main MR 668 analysis, rather than those weighted by the effect estimates obtained in the GWAS. We also performed 
medRxiv preprint doi: https://doi.org/10.1101/2022.01.13.22269233; this version posted January 13, 2022. The copyright holder for this preprint (which was not certified by peer review) is the author/funder, who has granted medRxiv a license to display the preprint in perpetuity.

It is made available under a CC-BY 4.0 International license .

669 MR using GRS comprising those genetic variants that replicated in independent datasets for chronotype

670 (55), insomnia (38) and sleep duration (57). Replication was determined based on genome-wide

671 significance in 23andMe for chronotype $(n=248,100)$ and insomnia ( $n=944,477)$, and $p<0.05$ in CHARGE

672 given the smaller sample size of this replication dataset $(n=47,180)$. Information on the genetic variants

673 used are described in Supplementary Table 11.

674

675 For insomnia, the SNPs used to assess Winner's curse were determined from a different GWAS of

676 insomnia to that used in the main analysis (56) and comprised a meta-analysis of UK Biobank and

677 23andMe (38). In an additional sensitivity analysis, we performed MR analysis using a GRS derived from

678 a larger number of SNPs identified at genome-wide significance in the meta-analysis and compared

679 estimates. Information on the genetic variants used are described in Supplementary Table 12. 
medRxiv preprint doi: https://doi.org/10.1101/2022.01.13.22269233; this version posted January 13, 2022. The copyright holder for this preprint (which was not certified by peer review) is the author/funder, who has granted medRxiv a license to display the preprint in perpetuity.

It is made available under a CC-BY 4.0 International license .

\section{Acknowledgements and Funding}

This research was conducted using the UK Biobank Resource under application number 16391. We thank the participants and researchers from the UK Biobank who contributed or collected data. We would also like to thank the research participants and employees of 23andMe for making this work possible. RCR, $\mathrm{LH}, \mathrm{JL}, \mathrm{DAL}$ and GDS are members of the MRC Integrative Epidemiology Unit at the University of Bristol funded by the Medical Research Council (MM_UU_00011/1 and MC_UU_00011/6). RCR is a de Pass VC research fellow at the University of Bristol. DAL is a British Heart Foundation Chair (CH/F/20/90003) and NIHR Senior Investigator (NF-0616-10102). This study was supported by the NIHR Biomedical

691 Research Centre at the University Hospitals Bristol NHS Foundation Trust and the University of Bristol.

692 The views expressed in this publication are those of the authors and not necessarily those of the

693 National Health Service, National Institute for Health Research, or Department of Health and Social Care.

694 RCR is a de Pass Vice Chancellor's Research Fellow at the University of Bristol.

The following members of the 23andMe Research Team contributed to this study: Stella Aslibekyan,

697 Adam Auton, Elizabeth Babalola, Robert K. Bell, Jessica Bielenberg, Katarzyna Bryc, Emily Bullis, Daniella

698 Coker, Gabriel Cuellar Partida, Devika Dhamija, Sayantan Das, Sarah L. Elson, Teresa Filshtein, Kipper

699 Fletez-Brant, Pierre Fontanillas, Will Freyman, Pooja M. Gandhi, Karl Heilbron, Barry Hicks, David A.

700 Hinds, Ethan M. Jewett, Yunxuan Jiang, Katelyn Kukar, Keng-Han Lin, Maya Lowe, Jey C. McCreight,

701 Matthew H. Mclntyre, Steven J. Micheletti, Meghan E. Moreno, Joanna L. Mountain, Priyanka

702 Nandakumar, Elizabeth S. Noblin, Jared O'Connell, Aaron A. Petrakovitz, G. David Poznik, Morgan

703 Schumacher, Anjali J. Shastri, Janie F. Shelton, Jingchunzi Shi, Suyash Shringarpure, Vinh Tran, Joyce Y.

704 Tung, Xin Wang, Wei Wang, Catherine H. Weldon, Peter Wilton, Alejandro Hernandez, Corinna Wong,

705 Christophe Toukam Tchakouté

708 Author contributions

710 RCR conceived the study and conducted the main analysis. KH conducted the replication analysis in

711 23andMe and JL assisted with sensitivity analyses. RCR and CV drafted the initial manuscript. All authors 712 assisted with interpretation, commented on drafts of the manuscript, and approved the final version. 
medRxiv preprint doi: https://doi.org/10.1101/2022.01.13.22269233; this version posted January 13, 2022. The copyright holder for this preprint (which was not certified by peer review) is the author/funder, who has granted medRxiv a license to display the preprint in perpetuity.

It is made available under a CC-BY 4.0 International license.

713 RCR is the guarantor and attests that all listed authors meet authorship criteria and that no others

714 meeting the criteria have been omitted.

715

\section{Competing interests}

$718 \mathrm{KH}, \mathrm{XW}$ and the 23andMe Research Team are employees of 23andMe and own stock and/or stock

719 options in 23andMe.

720

\section{Data sharing}

723 Summary-level data for UK Biobank and 23andMe are fully disclosed in the manuscript. Individual-level

724 data are not publicly available due to participant confidentiality, and in accordance with the IRB-

725 approved protocol under which the study was conducted. For details on accessing these studies, please

726 contact access@ukbiobank.ac.uk and apply.research@23andme.com.

\section{Figures}

729 Figure 1: Scenarios for spousal concordance of sleep traits

a)

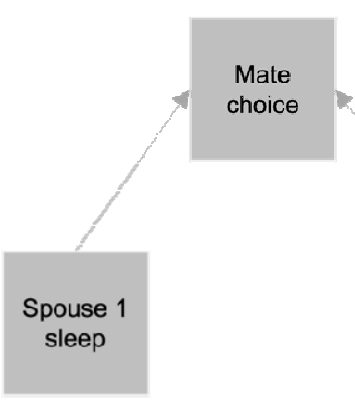

b)

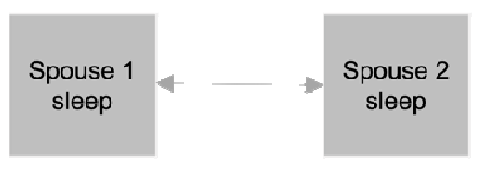

c)

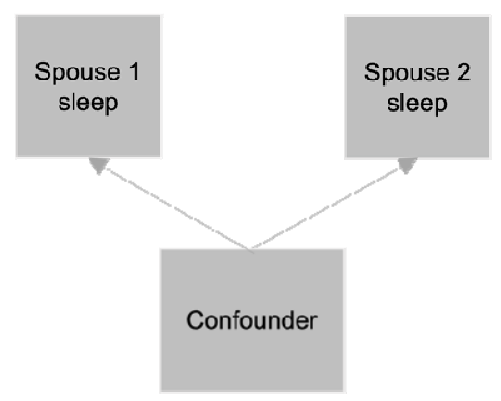

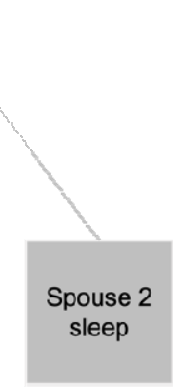

a) Assortative mating - individuals are more likely to select a mate with similar sleeping behaviour

b) Partner interaction - after partnership, spouses influence each other's sleeping behaviour

c) Confounding - shared environmental factors influence sleeping behaviour of the spouses 
medRxiv preprint doi: https://doi.org/10.1101/2022.01.13.22269233; this version posted January 13, 2022. The copyright holder for this preprint (which was not certified by peer review) is the author/funder, who has granted medRxiv a license to display the preprint in perpetuity.

It is made available under a CC-BY 4.0 International license.

735 Figure 2: Comparison of phenotypic correlations between spouses in UK Biobank

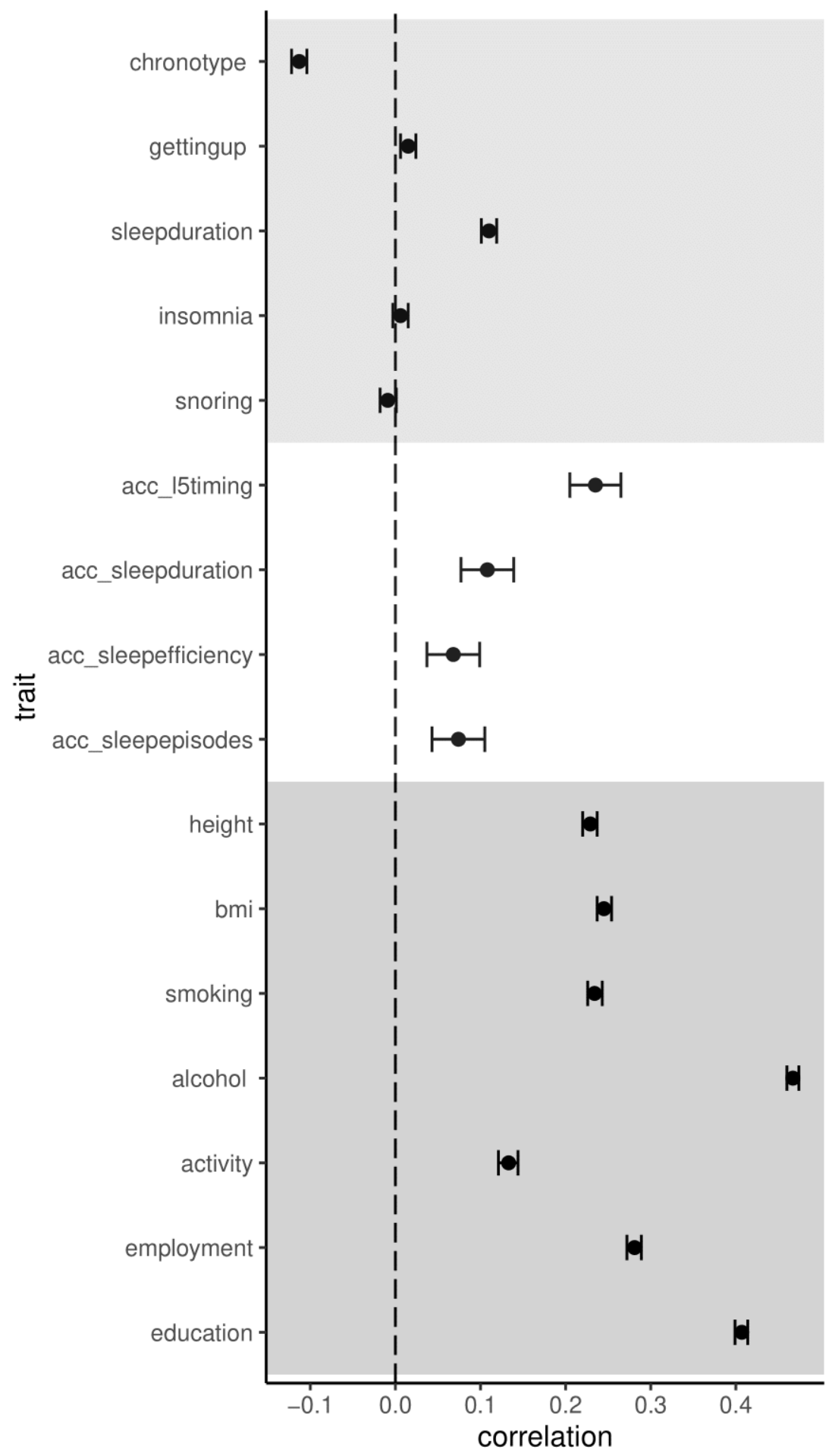

Acc_ = accelerometer-derived measure 
medRxiv preprint doi: https://doi.org/10.1101/2022.01.13.22269233; this version posted January 13, 2022. The copyright holder for this preprint (which was not certified by peer review) is the author/funder, who has granted medRxiv a license to display the preprint in perpetuity.

It is made available under a CC-BY 4.0 International license .

738 Figure 3: Spousal phenotypic correlations between sleep traits in UK Biobank and 23andMe

Sleep Trait

Chronotype
UK Biobank
23andMe

Sleep duration

UK Biobank

23andMe

Insomnia

UK Biobank

23andMe

Snoring

UK Biobank

23andMe
Correlation $(95 \% \mathrm{Cl})$
$-0.11(-0.12,-0.10)$

$-0.13(-0.14,-0.12)$

$0.02(0.01,0.03)$

$0.07(0.06,0.07)$

$-0.01(-0.02,-0.00)$

$0.05(0.03,0.07)$

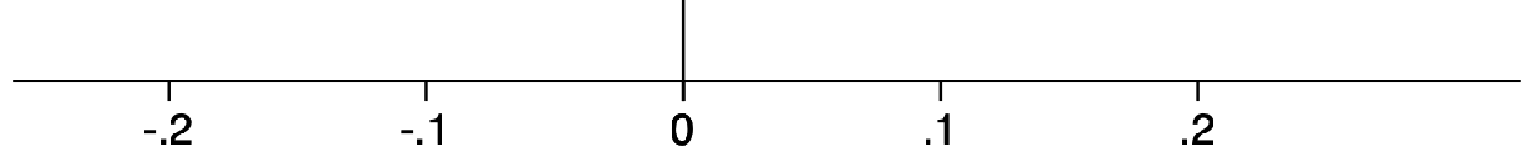

739 
medRxiv preprint doi: https://doi.org/10.1101/2022.01.13.22269233; this version posted January 13, 2022. The copyright holder for this preprint (which was not certified by peer review) is the author/funder, who has granted medRxiv a license to display the preprint in perpetuity.

It is made available under a CC-BY 4.0 International license.

740 Figure 4: Comparison of multivariable and Mendelian randomization estimates in UK Biobank

741 Estimates represent the mean difference in the spouse's sleep trait per SD increase in an individual's

742 own sleep trait, with the exception of snoring for which estimates represent risk difference.

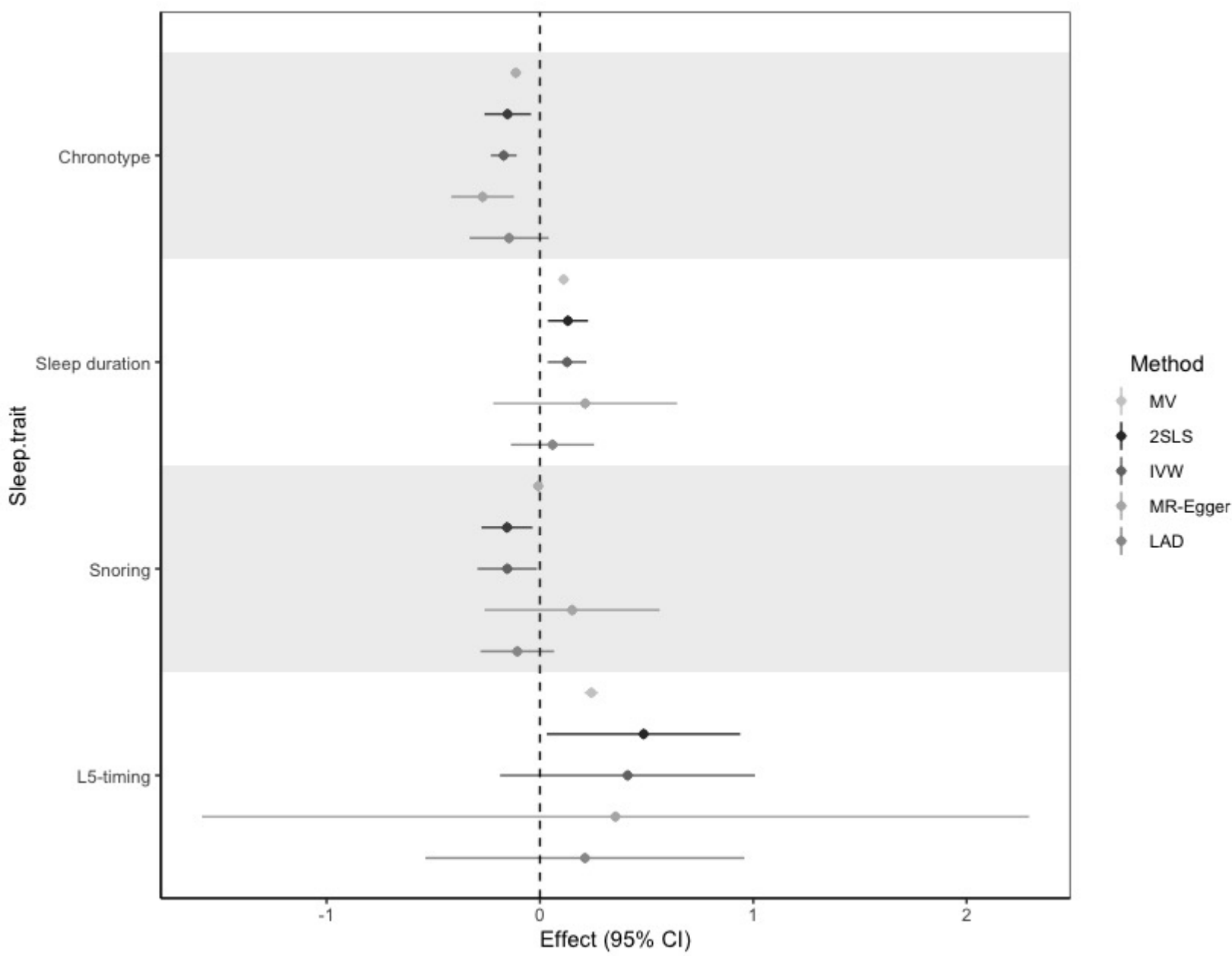

743

$744 \mathrm{MV}=$ multivariable regression, $2 \mathrm{SLS}=$ two-stage least squares, IVW = inverse-variance weighted, MR-

745 Egger $=$ MR-Egger approach, LAD = least absolute deviation 
medRxiv preprint doi: https://doi.org/10.1101/2022.01.13.22269233; this version posted January 13, 2022. The copyright holder for this preprint (which was not certified by peer review) is the author/funder, who has granted medRxiv a license to display the preprint in perpetuity.

746 
medRxiv preprint doi: https://doi.org/10.1101/2022.01.13.22269233; this version posted January 13, 2022. The copyright holder for this preprint (which was not certified by peer review) is the author/funder, who has granted medRxiv a license to display the preprint in perpetuity.

It is made available under a CC-BY 4.0 International license.

747

748

749

750

Table 1: Sleep traits among male and female spouses in UK Biobank

\begin{tabular}{|c|c|c|c|}
\hline & & Female spouses & Male spouses \\
\hline Self-reported traits & $\mathrm{N}$ (spouse-pairs) & Mean (SD) & Mean (SD) \\
\hline Age at baseline assessment & 47,420 & $56.8(7.3)$ & $58.5(7.3)$ \\
\hline \multirow[t]{2}{*}{ Sleep duration } & 47,169 & $7.3(1.1)$ & $7.2(1.0)$ \\
\hline & & $\%(n)$ & $\%(n)$ \\
\hline Chronotype & 47,235 & & \\
\hline Extreme evening preference & & $6.4(3,003)$ & $7.0(3,291)$ \\
\hline Intermediate evening preference & & $26.2(12,360)$ & $24.6(11,629)$ \\
\hline No preference & & $8.4(3,980)$ & $12.8(6,047)$ \\
\hline Intermediate morning preference & & $35.2(16,609)$ & $32.9(15,558)$ \\
\hline Extreme morning preference & & $23.9(11,283)$ & $22.6(10,710)$ \\
\hline Ease of waking up & 47,325 & & \\
\hline Not at all easy & & $4.2(2,007)$ & $1.9(889)$ \\
\hline Not very easy & & $15.7(7,416)$ & $9.3(4,400)$ \\
\hline Fairly easy & & $52.7(24,930)$ & $48.6(23,010)$ \\
\hline Very easy & & $27.4(12,972)$ & $40.2(19,026)$ \\
\hline Insomnia symptoms frequency & 47,369 & & \\
\hline Never/rarely & & $17.5(8,291)$ & $30.4(14,393)$ \\
\hline Sometimes & & $50.3(23,828)$ & $46.0(21,789)$ \\
\hline Usually & & $32.2(15,250)$ & $23.6(11,187)$ \\
\hline \multicolumn{4}{|l|}{ Snoring } \\
\hline No & 45,546 & $69.8(31,785)$ & $46.4(21,135)$ \\
\hline Yes & & $30.2(13,761)$ & $53.6(24,411)$ \\
\hline Accelerometer-derived traits & & Mean (SD) & Mean (SD) \\
\hline Age at accelerometer assessment & 3,454 & $63.1(6.9)$ & $64.8(7.0)$ \\
\hline L5-timing & 3,454 & $27.3(1.0)$ & $27.3(1.0)$ \\
\hline Sleep duration & 3,454 & $7.5(0.8)$ & $7.3(0.9)$ \\
\hline Nocturnal sleep episodes & 3,454 & $16.9(3.5)$ & $17.6(3.8)$ \\
\hline Sleep efficiency & 3,454 & $0.78(0.06)$ & $0.75(0.07)$ \\
\hline
\end{tabular}

751

752

753

754

755

756

757

758

759

\section{Tables}


medRxiv preprint doi: https://doi.org/10.1101/2022.01.13.22269233; this version posted January 13, 2022. The copyright holder for this preprint (which was not certified by peer review) is the author/funder, who has granted medRxiv a license to display the preprint in perpetuity.

It is made available under a CC-BY 4.0 International license .

760 Table 2: Multivariable regression and Mendelian randomization analysis to assess associations between 761 sleep traits among UK Biobank spouse-pairs 762

\begin{tabular}{|c|c|c|c|c|c|c|c|c|c|c|c|c|}
\hline \multirow[b]{2}{*}{ Sleep trait } & \multirow[b]{2}{*}{$\begin{array}{l}\mathrm{N} \\
\text { (pairs) }\end{array}$} & \multirow[b]{2}{*}{$\begin{array}{l}\text { Risk/mean } \\
\text { difference }\end{array}$} & \multicolumn{3}{|c|}{ Multivariable regression } & \multicolumn{7}{|c|}{ Mendelian randomization (2SLS) } \\
\hline & & & SE & ClL & $\mathrm{CIU}$ & P-value & $\begin{array}{l}\text { Risk/mean } \\
\text { difference }\end{array}$ & SE & $\mathrm{ClL}$ & $\mathrm{CIU}$ & P-value & $\begin{array}{l}\text { z-test for } \\
\text { difference }\end{array}$ \\
\hline \multicolumn{13}{|l|}{ Self-reported } \\
\hline Chronotype & 47,235 & -0.113 & 0.005 & -0.122 & -0.104 & $2.42 \mathrm{E}-135$ & -0.152 & 0.055 & -0.26 & -0.042 & 0.006 & 0.480 \\
\hline Ease of waking & 47,325 & 0.015 & 0.005 & 0.005 & 0.023 & $2.00 \mathrm{E}-03$ & -0.039 & 0.079 & -0.193 & 0.116 & 0.625 & 0.503 \\
\hline Sleep duration & 47,050 & 0.111 & 0.005 & 0.102 & 0.120 & 7.97E-126 & 0.131 & 0.048 & 0.037 & 0.226 & 0.007 & 0.679 \\
\hline Insomnia & 47,369 & 0.005 & 0.005 & -0.004 & 0.014 & 0.304 & -0.046 & 0.054 & -0.151 & 0.058 & 0.386 & 0.347 \\
\hline Snoring & 45,546 & -0.008 & 0.004 & -0.017 & 0.000 & 0.051 & -0.154 & 0.061 & -0.274 & -0.035 & 0.011 & 0.017 \\
\hline \multicolumn{13}{|c|}{ Accelerometer-derived } \\
\hline L5-timing & 3,454 & 0.241 & 0.016 & 0.209 & 0.272 & $1.56 \mathrm{E}-50$ & 0.486 & 0.232 & 0.032 & 0.939 & 0.036 & 0.292 \\
\hline Sleep duration & 3,454 & 0.108 & 0.016 & 0.077 & 0.140 & $1.38 \mathrm{E}-11$ & 0.132 & 0.131 & -0.124 & 0.387 & 0.312 & 0.856 \\
\hline Sleep episodes & 3,454 & 0.069 & 0.016 & 0.038 & 0.100 & $1.63 \mathrm{E}-05$ & -0.267 & 0.247 & -0.751 & 0.217 & 0.28 & 0.175 \\
\hline Sleep efficiency & 3.454 & 0.075 & 0.016 & 0.043 & 0.106 & $3.84 \mathrm{E}-06$ & 0.024 & 0.138 & -0.246 & 0.295 & 0.859 & 0.714 \\
\hline
\end{tabular}

763

764 Estimates represent the mean difference in the spouse's sleep trait per SD increase in an individual's

765

766

767

768

769

770

771 own sleep trait, with the exception of snoring for which estimates represent risk difference.

Multivariable regression was adjusted for age at assessment and assessment centre for both spouses. Mendelian randomization was adjusted for age at assessment, assessment centre, genotyping chip and 10 genetic principal components (PCs) for both spouses. 2SLS = Two-stage least squares. 
medRxiv preprint doi: https://doi.org/10.1101/2022.01.13.22269233; this version posted January 13, 2022. The copyright holder for this preprint (which was not certified by peer review) is the author/funder, who has granted medRxiv a license to display the preprint in perpetuity.

It is made available under a CC-BY 4.0 International license.

772 Table 3: Genetic risk score (GRS) associations with sleep traits in UK Biobank

773

\begin{tabular}{lrrrrrr} 
Trait & N (pairs) & N SNPs & \multicolumn{2}{c}{ Female spouses } & \multicolumn{2}{c}{ Male spouses $^{2}$} \\
Self-report & & \multicolumn{2}{c}{ Partial R $^{2}$} & F-statistic & Partial R $^{2}$ & F-statistic \\
\hline Chronotype & 47,235 & 156 & 0.013 & 604 & 0.012 & 548 \\
Ease of waking up & 47,325 & 79 & 0.006 & 273 & 0.006 & 278 \\
Sleep duration & 47,050 & 70 & 0.006 & 279 & 0.005 & 239 \\
Insomnia symptoms & 47,369 & 40 & 0.004 & 192 & 0.003 & 161 \\
Snoring & 45,546 & 38 & 0.003 & 142 & 0.003 & 132 \\
Accelerometer-derived & & & & & & \\
\hline Least-active 5 hour timing & 3,454 & 6 & 0.003 & 8.5 & 0.006 & 19.2 \\
Sleep duration & 3,454 & 11 & 0.005 & 17.2 & 0.014 & 48.3 \\
Number of sleep episodes & 3,454 & 22 & 0.014 & 47.2 & 0.010 & 33.2 \\
Sleep efficiency & 3,454 & 5 & 0.001 & 4.8 & 0.005 & 17.3 \\
\hline
\end{tabular}

774

775 Estimates for variance explained are adjusted for age, assessment centre, genotyping chip and top 10

776 principal components

777

778 
medRxiv preprint doi: https://doi.org/10.1101/2022.01.13.22269233; this version posted January 13, 2022. The copyright holder for this preprint (which was not certified by peer review) is the author/funder, who has granted medRxiv a license to display the preprint in perpetuity.

It is made available under a CC-BY 4.0 International license.

\section{Box 1: Sleep trait glossary}

\section{UK Biobank self-reported measures}

Chronotype (diurnal preference) - Whether a person identifies as being a 'morning person' or an 'evening person' (ordered categorical variable of "definitely a morning person", "more of a morning than an evening person", "do not know", more of an evening than a morning person", and "definitely an evening person")

Ease of waking - Whether a person finds it easy to wake up in the morning (ordered categorical variable of "not at all easy", "not very easy", "fairly easy", "very easy")

Sleep duration - Average number of hours slept in 24 hours, including naps (continuous variable, hours)

Insomnia symptoms - Person has trouble falling asleep at night or wakes up in the middle of the night (ordered categorical variable of "never/rarely", "sometimes", and "usually")

Snoring - Whether a person reports that their partner or a close relative or friend complains about their snoring (binary variable of "yes" or "no")

\section{UK Biobank accelerometer measures}

L5-timing (activity timing) - Timing of the least active 5 hours of the day (continuous variable of hours elapsed since previous midnight). L5-timing represents activity later in the day (i.e. inversely related to morning preference chronotype).

Sleep duration - Average number of hours of sleep per night (continuous variable, hours)

Number of sleep episodes - Average number of nocturnal sleep episodes separated by at least 5 minutes of wakefulness per night (continuous variable, number of episodes)

Sleep efficiency - Sleep duration divided by time in bed (equivalent to time in bed) (continuous variable, proportion) 
medRxiv preprint doi: https://doi.org/10.1101/2022.01.13.22269233; this version posted January 13, 2022. The copyright holder for this preprint (which was not certified by peer review) is the author/funder, who has granted medRxiv a license to display the preprint in perpetuity.

It is made available under a CC-BY 4.0 International license.

\section{References}

1. Krueger PM, Friedman EM. Sleep duration in the United States: a cross-sectional population-based study. Am J Epidemiol. 2009;169(9):1052-63.

\section{Calem M, Bisla J, Begum A, Dewey M, Bebbington PE, Brugha $T$, et al. Increased} prevalence of insomnia and changes in hypnotics use in England over 15 years: analysis of the 1993, 2000, and 2007 National Psychiatric Morbidity Surveys. Sleep. 2012;35(3):377-84.

3. Kocevska D, Lysen TS, Dotinga A, Koopman-Verhoeff ME, Luijk M, Antypa N, et al. Sleep characteristics across the lifespan in 1.1 million people from the Netherlands, United Kingdom and United States: a systematic review and meta-analysis. Nat Hum Behav. 2020.

4. Van Someren EJ. Circadian rhythms and sleep in human aging. Chronobiol Int. 2000;17(3):233-43.

5. Fischer D, Lombardi DA, Marucci-Wellman H, Roenneberg T. Chronotypes in the US Influence of age and sex. PLoS One. 2017;12(6):e0178782.

6. Uehli K, Mehta AJ, Miedinger D, Hug K, Schindler C, Holsboer-Trachsler E, et al. Sleep problems and work injuries: a systematic review and meta-analysis. Sleep Med Rev. 2014;18(1):61-73.

7. Hafner M, Stepanek M, Taylor J, Troxel WM, van Stolk C. Why Sleep Matters-The Economic Costs of Insufficient Sleep: A Cross-Country Comparative Analysis. Rand Health Q. 2017;6(4):11.

8. Sofi F, Cesari F, Casini A, Macchi C, Abbate R, Gensini GF. Insomnia and risk of cardiovascular disease: a meta-analysis. Eur J Prev Cardiol. 2014;21(1):57-64.

9. Cappuccio FP, D'Elia L, Strazzullo P, Miller MA. Quantity and quality of sleep and incidence of type 2 diabetes: a systematic review and meta-analysis. Diabetes Care. 2010;33(2):414-20.

10. Liu J, Richmond RC, Bowden J, Barry C, Dashti HS, Daghlas I, et al. Assessing the causal role of sleep traits on glycated haemoglobin: a Mendelian randomization study. Diabetes Care. 2022; (in press).

\section{Baglioni C, Battagliese G, Feige B, Spiegelhalder K, Nissen C, Voderholzer U, et al.} Insomnia as a predictor of depression: a meta-analytic evaluation of longitudinal epidemiological studies. J Affect Disord. 2011;135(1-3):10-9.

12. Haus EL, Smolensky MH. Shift work and cancer risk: potential mechanistic roles of circadian disruption, light at night, and sleep deprivation. Sleep Med Rev. 2013;17(4):273-84. 13. Richter K, Adam S, Geiss L, Peter L, Niklewski G. Two in a bed: The influence of couple sleeping and chronotypes on relationship and sleep. An overview. Chronobiol Int. 2016;33(10):1464-72.

14. Luo S. Assortative mating and couple similarity: Patterns, mechanisms, and consequences. Social and Personality Psychology Compass. 2017;11(8):e12337.

15. Di Castelnuovo A, Quacquaruccio G, Donati MB, de Gaetano G, Iacoviello L. Spousal concordance for major coronary risk factors: a systematic review and meta-analysis. Am J Epidemiol. 2009;169(1):1-8.

16. Grant JD, Heath AC, Bucholz KK, Madden PA, Agrawal A, Statham DJ, et al. Spousal concordance for alcohol dependence: evidence for assortative mating or spousal interaction effects? Alcohol Clin Exp Res. 2007;31(5):717-28. 
medRxiv preprint doi: https://doi.org/10.1101/2022.01.13.22269233; this version posted January $13,2022$. The copyright holder for this preprint (which was not certified by peer review) is the author/funder, who has granted medRxiv a license to display the preprint in perpetuity. It is made available under a CC-BY 4.0 International license .

834 17. Eeckhaut MC, Stanfors MA. Educational assortative mating, gender equality, and income differentiation across Europe: A simulation study. Acta Sociologica. 2021;64(1):48-69. 18. Nagoshi CT, Johnson RC, Danko GP. Assortative mating for cultural identification as indicated by language use. Behavior genetics. 1990;20(1):23-31. 19. Howe L, Battram T, Morris TT, Hartwig FP, Hemani G, Davies NM, et al. Assortative mating and within-spouse pair comparisons. PLoS Genet. 2021;17(11):e1009883. 20. Pankhurst FP, Horne JA. The influence of bed partners on movement during sleep. Sleep. 1994;17(4):308-15.

842 21. Meadows R, Arber S, Venn S, Hislop J, Stanley N. Exploring the interdependence of couples' rest-wake cycles: an actigraphic study. Chronobiol Int. 2009;26(1):80-92.

844 22. Arber S, Hislop J, Bote M, Meadows R. Gender Roles and Women's Sleep in Mid and 845 Later Life: A Quantiative Approach. Sociological Research Online. 2007;12(5):182-99.

846 23. Ulfberg J, Carter N, Talback M, Edling C. Adverse health effects among women living with heavy snorers. Health Care Women Int. 2000;21(2):81-90.

848 24. Davey Smith G, Hemani G. Mendelian randomization: genetic anchors for causal inference in epidemiological studies. Hum Mol Genet. 2014;23(R1):R89-98. 25. Davies NM, Holmes MV, Davey Smith G. Reading Mendelian randomisation studies: a guide, glossary, and checklist for clinicians. BMJ. 2018;362:k601. 26. Davey Smith G, Ebrahim S. 'Mendelian randomization': can genetic epidemiology contribute to understanding environmental determinants of disease? Int J Epidemiol. 2003;32(1):1-22.

855 27. Davies NM, Howe L, Brumpton B, Havdahl A, Evans DM, Davey Smith G. Within family 856 Mendelian randomization studies. Hum Mol Genet. 2019;28(R2):R170-R9.

857 28. Baud A, Mulligan MK, Casale FP, Ingels JF, Bohl CJ, Callebert J, et al. Genetic Variation in the Social Environment Contributes to Health and Disease. PLoS Genet. 2017;13(1):e1006498. 29. Domingue BW, Belsky DW, Fletcher JM, Conley D, Boardman JD, Harris KM. The social genome of friends and schoolmates in the National Longitudinal Study of Adolescent to Adult Health. Proc Natl Acad Sci U S A. 2018;115(4):702-7. 30. Kong A, Thorleifsson G, Frigge ML, Vilhjalmsson BJ, Young Al, Thorgeirsson TE, et al. The nature of nurture: Effects of parental genotypes. Science. 2018;359(6374):424-8. 31. Young Al, Benonisdottir S, Przeworski M, Kong A. Deconstructing the sources of genotype-phenotype associations in humans. Science. 2019;365(6460):1396-400. effects in humans. Nat Hum Behav. 2021;5(3):399-406. 33. Robinson MR, Kleinman A, Graff M, Vinkhuyzen AAE, Couper D, Miller MB, et al. Genetic evidence of assortative mating in humans. Nature Human Behaviour. 2017;1(1):0016. 34. Howe L, Lawson DJ, Davies NM, St Pourcain B, Lewis SJ, Davey Smith G, et al. Genetic evidence for assortative mating on alcohol consumption in the UK Biobank. Nat Commun. 2019;10(1):5039. 35. van Hees VT, Sabia S, Jones SE, Wood AR, Anderson KN, Kivimaki M, et al. Estimating sleep parameters using an accelerometer without sleep diary. Sci Rep. 2018;8(1):12975. behaviour. Nat Commun. 2019;10(1):1585. 
medRxiv preprint doi: https://doi.org/10.1101/2022.01.13.22269233; this version posted January $13,2022$. The copyright holder for this preprint (which was not certified by peer review) is the author/funder, who has granted medRxiv a license to display the preprint in perpetuity.

It is made available under a CC-BY 4.0 International license.

878 37. Barry C, Liu J, Richmond R, Rutter MK, Lawlor DA, Dudbridge F, et al. Exploiting collider

879 bias to apply two-sample summary data Mendelian randomization methods to one-sample

880 individual level data. medRxiv. 2020:2020.10.20.20216358.

881 38. Jansen PR, Watanabe K, Stringer S, Skene N, Bryois J, Hammerschlag AR, et al. Genome-

882 wide analysis of insomnia in 1,331,010 individuals identifies new risk loci and functional

883 pathways. Nat Genet. 2019;51(3):394-403.

884 39. Randler C, Kretz S. Assortative mating in morningness-eveningness. Int J Psychol.

885 2011;46(2):91-6.

886 40. Walters EM, Phillips AJK, Mellor A, Hamill K, Jenkins MM, Norton PJ, et al. Sleep and

887 wake are shared and transmitted between individuals with insomnia and their bed-sharing

888 partners. Sleep. 2020;43(1).

889 41. Fry A, Littlejohns TJ, Sudlow C, Doherty N, Adamska L, Sprosen T, et al. Comparison of

890 Sociodemographic and Health-Related Characteristics of UK Biobank Participants With Those of

891 the General Population. Am J Epidemiol. 2017;186(9):1026-34.

892 42. Munafo MR, Tilling K, Taylor AE, Evans DM, Davey Smith G. Collider scope: when

893 selection bias can substantially influence observed associations. Int J Epidemiol.

894 2018;47(1):226-35.

895 43. Torvik FA, Gustavson K, Roysamb E, Tambs K. Health, health behaviors, and health

896 dissimilarities predict divorce: results from the HUNT study. BMC Psychol. 2015;3(1):13.

897 44. https://www.sleepfoundation.org/sites/default/files/inline-

898 files/2005 summary of findings.pdf 2005 [

899 45. Gunn HE, Buysse DJ, Matthews KA, Kline CE, Cribbet MR, Troxel WM. Sleep-Wake

900 Concordance in Couples Is Inversely Associated With Cardiovascular Disease Risk Markers.

901 Sleep. 2017;40(1).

902 46. Sudlow C, Gallacher J, Allen N, Beral V, Burton P, Danesh J, et al. UK biobank: an open

903 access resource for identifying the causes of a wide range of complex diseases of middle and

904 old age. PLoS Med. 2015;12(3):e1001779.

905 47. Bycroft C, Freeman C, Petkova D, Band G, Elliott LT, Sharp K, et al. The UK Biobank

906 resource with deep phenotyping and genomic data. Nature. 2018;562(7726):203-+.

907 48. Mitchell R, Hemani G, Dudding T, Corbin L, Harrison S, Paternoster L. UK Biobank

908 Genetic Data: MRC-IEU Quality Control, Version 2.

909 https://doiorg/105523/bris1ovaau5sxunp2cv8rcy88688v. 2019.

910 49. Doherty A, Jackson D, Hammerla N, Plotz T, Olivier P, Granat MH, et al. Large Scale

911 Population Assessment of Physical Activity Using Wrist Worn Accelerometers: The UK Biobank

912 Study. Plos One. 2017;12(2).

913 50. van Hees VT, Sabia S, Anderson KN, Denton SJ, Oliver J, Catt M, et al. A Novel, Open

914 Access Method to Assess Sleep Duration Using a Wrist-Worn Accelerometer. Plos One.

$915 \quad 2015 ; 10(11)$.

916 51. Jones SE, van Hees VT, Mazzotti DR, Marques-Vidal P, Sabia S, van der Spek A, et al.

917 Genetic studies of accelerometer-based sleep measures in 85,670 individuals yield new insights

918 into human sleep behaviour. bioRxiv. 2018.

919 52. van Hees VT, Sabia S, Jones SE, Wood AR, Anderson KN, Kivimaki M, et al. Estimating

920 sleep parameters using an accelerometer without sleep diary. Sci Rep-Uk. 2018;8.

921 53. https://www.23andme.com/ancestry-composition-guide/ [ 
medRxiv preprint doi: https://doi.org/10.1101/2022.01.13.22269233; this version posted January 13, 2022. The copyright holder for this preprint (which was not certified by peer review) is the author/funder, who has granted medRxiv a license to display the preprint in perpetuity.

It is made available under a CC-BY 4.0 International license.

922 54. Durand EY, Do CB, Mountain JL, Macpherson JM. Ancestry Composition: A Novel, 923 Efficient Pipeline for Ancestry Deconvolution. bioRxiv. 2014:010512.

$92455 . \quad J o n e s$ SE, Lane JM, Wood AR, van Hees VT, Tyrrell J, Beaumont RN, et al. Genome-wide 925 association analyses of chronotype in 697,828 individuals provides insights into circadian 926 rhythms. Nat Commun. 2019;10(1):343.

927 56. Lane JM, Jones SE, Dashti HS, Wood AR, Aragam KG, van Hees VT, et al. Biological and 928 clinical insights from genetics of insomnia symptoms. Nat Genet. 2019;51(3):387-93.

929 57. Dashti HS, Jones SE, Wood AR, Lane JM, van Hees VT, Wang H, et al. Genome-wide

930 association study identifies genetic loci for self-reported habitual sleep duration supported by 931 accelerometer-derived estimates. Nat Commun. 2019;10(1):1100.

932 58. Campos Al, Garcia-Marin LM, Byrne EM, Martin NG, Cuellar-Partida G, Renteria ME. 933 Insights into the aetiology of snoring from observational and genetic investigations in the UK 934 Biobank. Nat Commun. 2020;11(1):817.

935 59. Hemani G, Zheng J, Elsworth B, Wade KH, Haberland V, Baird D, et al. The MR-Base 936 platform supports systematic causal inference across the human phenome. Elife. 2018;7.

937 60. Burgess S, Dudbridge F, Thompson SG. Combining information on multiple instrumental 938 variables in Mendelian randomization: comparison of allele score and summarized data 939 methods. Stat Med. 2016;35(11):1880-906.

940 61. Bowden J, Davey Smith G, Burgess S. Mendelian randomization with invalid instruments: 941 effect estimation and bias detection through Egger regression. Int J Epidemiol. 2015;44(2):51294225.

943 62. Bowden J, Davey Smith G, Haycock PC, Burgess S. Consistent Estimation in Mendelian 944 Randomization with Some Invalid Instruments Using a Weighted Median Estimator. Genet 945 Epidemiol. 2016;40(4):304-14. 